\title{
Increasing the Capacities of Cable Cars for Use in Public Transport
}

\author{
Sergej Težak, Ph.D., Drago Sever, Ph. D., Marjan Lep, Ph.D. \\ University of Maribor, Slovenia
}

\begin{abstract}
This paper examines the advantages and disadvantages of cable cars in public transport within urban areas. The advantages of cable car transport compared to other modes of transport are its quiet operation with an environmentally-acceptable electric drive and the possibility of transporting passengers above the ground, which can provide additional transport dimensions within urban centers. However, cable cars have some disadvantages, especially their smaller capacities in relation to other modes of transport within the urban environment. Today's built cable cars have capacities up to 2,000 persons/h for aerial tramways (or jig-back ropeways) and up to 4,000 persons/h for gondolas.
\end{abstract}

Solutions are introduced in this paper as to how the current cable car technologies can increase the capacities of these devices. This can be achieved by concentrating on the vehicles (cabins) on gondola lines and by using multiple platforms at starting stations and final stations. It also provides a solution for intermediate stations, at which vehicles can be stopped independent of other vehicles on the line.

Keywords: Cable cars, cableways, gondolas, public transport, geometric modeling, capacity, boarding

\section{Introduction}

The mobility of the population has always been important within the context of socioeconomic and technical-technological points of view. However, there is an increasingly important ecological aspect regarding sustainable development. The main cases of technical-technological aspects can be seen in motorized vehicles, where, through emission standards, the harm from exhaust gases in the environment and in regard to the population is reduced.

Vehicles that use electricity for driving have minimum direct impacts on the environment, especially if the electricity is produced in such a way that it does not pollute the environment. In any event, for densely-populated urban environments, such as large cities, it would be extremely favorable if people were to use electrically-driven 
vehicles for mobility. This would represent the minimum impact on the environmentno harmful exhaust emissions, which is still a major problem in most cities. Electricpowered trams, trolleybuses, metros, and, more recently, electric cars and buses already are used in cities. However, a problem with today's urban mobility is that it takes place mainly at ground level, and, as a result, streets and city roads are very busy, thus causing congestion. In larger cities, where the demands for transportation services are greater, transport also takes place underground using subways. Regrettably, spaces at ground levels in cities remain unexploited.

As a subsystem of a transport system, cable car transport holds a specific place because it makes accessible those places that are interesting from the aspect of tourism as well as those that are difficult to access via other transport subsystems (Sever 2002). Cable car transport is carried out using cable cars that encompass all-aerial cable car facilities. Cable cars use ropes and are usually electrically-powered, but they rarely are used in urban areas; rather, they are used primarily for tourism, especially winter ski resorts. In these areas, in addition to technological efficiency, the economic efficiency of cable car transport has improved, as presented by Brida et al. (2014). In urban environments, funiculars, which came into service as early as the $19^{\text {th }}$ century, mostly are used to transport people to locations that are at higher altitudes, especially in regard to tourism; however, they work only over short distances depending on the terrain relief.

Cable cars, especially those operating above ground level (aerial cable cars), have great potential for use in urban environments. Their operation can relieve traffic on the surface in the cities. The problem is that they do not have large capacities for transporting passengers; the maximum capacity for aerial cable cars is 4,000 persons $/ \mathrm{h}$. Therefore, they are not competitive relative to other options of passenger transport in urban centers. However, in larger cities such as Medellin, New York, Portland, Caracas, Rio de Janeiro, and La Paz, they already are used as parts of the public transport network. Research towards the direction that aerial cable cars should have greater capacities has not been conducted to date. Funiculars are used for greater capacities in mountainous areas, which go on or under the surface and are faster.

The purpose of this paper is to present new solutions that use existing technology for passenger transport by rope, so that this mode of transport could become more competitive compared to other types of passenger transport in urban areas. Comparisons with existing modes of transport in urban environments also are made and presented, as are the potential advantages and disadvantages of the proposed solutions.

\section{Overview of Previous Research}

The uses of cable cars in non-urban environments, especially in mountainous areas and for tourism, have been well studied, but the use of these systems in urban areas and city centers as part of public transport networks have not. Technical solutions on cable cars are fairly well described in various books (such as Doppelmayr 1997; Günthner 1999; Nejez 2006).

The issue regarding the uses of different types of cable cars and comparisons with other transport systems in an urban environment are presented in a study by Clement-Werny 
et al. (2011), in which an economic analysis of the construction of existing cable car systems also was given. Experience using gondolas as public transport has occurred more often in various cities of South America. In Medellin, aerial gondola lines were built for use in public transport because bus transport was very badly organized and the transport area is mountainous and difficult to access. Gondolas were built to improve accessibility for poor people who live in these areas of the city. Interestingly, it was observed that better transport accessibility using cable cars also raised real estate prices near the cable car stations, which also was mentioned in research by Bocareo et al. (2014). As Medellin is a representative example of the use of cable cars in public transport, this case has been discussed by many authors, including Heinrichs and Bernet (2014), Dávila (2013), Bocareo et al. (2014), and Brand and Dávila (2011).

Recently, La Paz built gondolas as part of its public transport system, with three gondolas operating with a total length of $10 \mathrm{~km}$ (ISR 2015). Cableways also have been built as public transport in the U.S. Portland, Oregon, has an aerial tramway that carries commuters between the Oregon Health \& Science University campus (with a hospital) and the city's South Waterfront district, where there is a lower station adjacent to a stop on the Portland Streetcar line. In Telluride and the Montain Village in Colorado, a gondola serves as free public transportation. In other parts of the world, cable cars are used as parts of urban transport systems primarily for tourism purposes. Future trends in the use of cable cars also were indicated by Wu et al. (2013), who noted that cable cars in China play an important role in diverse urban transport networks.

\section{Characteristics of Cable Car Transport and Comparison with Other Modes of Transport}

Cable car transport is carried out using aerial cable cars, surface lifts, and funiculars (Doppelmayr 1997). With ski lifts and funiculars (or funicular railways), passengers are carried above ground level; with aerial cable cars, passengers are carried in the air. For this reason, aerial cable cars are more suitable for use in urban environments because they do not burden existing urban traffic routes.

Aerial cable cars have the following advantages compared with other transport modes:

- Independent transport relief (suitable for hilly areas)

- Powered by electricity

- No $\mathrm{CO}_{2}$ emissions, if renewable energy is used for electricity

- No exhaust emissions

- Significantly-reduced noise emissions (Nikšić 2010)

- No need of surfaces for transport

- High level of traffic safety (according to Oplatka [2008], the rate of injuries in Switzerland was 7,8 persons per 100 million passengers)

- Comfortable transport in the air by rope (vibrations occur only when vehicles pass over the roller batteries) 
- No need for the additional weight of a drive mechanism and fuel in the vehicle

Despite their good characteristics, aerial cable cars also have certain limitations:

- Speed limited to $12 \mathrm{~m} / \mathrm{s}$ or $43,2 \mathrm{~km} / \mathrm{h}$

- Capacity limited to 4,000 persons/h

- Suitable only for distances up to $7 \mathrm{~km}$ (gondolas with intermediate stations)

- Wind resistance, normally up to $18 \mathrm{~m} / \mathrm{s}(65 \mathrm{~km} / \mathrm{h})$, bi-cable systems $90 \mathrm{~km} / \mathrm{h}$

- Extensive maintenance and controls

- Difficult to rescue people from aerial cable cars

- Expensive infrastructure (for faster detachable cable cars)

- No heating or air conditioning in cabins

- Potential negative visual impacts of cable cars

According to operating principles, aerial cable cars are divided into aerial tramways and gondolas. Aerial tramways (jig-back ropeways, reversible aerial ropeways) transport passengers using one or two cabins that move back and forth on cables. Their maximum speed is $12 \mathrm{~m} / \mathrm{s}$ or $43.2 \mathrm{~km} / \mathrm{h}$ (CEN 2004). With only two cabins, they can overcome greater inclines than gondolas, the span between the pylons can be extraordinarily long (more than $1 \mathrm{~km}$ ) so they can overcome major gaps and precipices, and they are suitable for distances up to $3 \mathrm{~km}$. The cabins stop completely at stations, so passengers have enough time to enter or exit. As only two cabins are available, they have small capacities (200 persons per cabin, max. 2,000 persons/h), and the average waiting time of passengers at the station is longer; the times of entry and exit (dwell times) also are longer than gondolas.

Gondolas are uni-directional aerial cable cars with circulating vehicles (cabins). They consist of several cabins that can carry up to 30 persons each and have greater capacities than aerial cars, up to 4,000 persons/h. The speed is slower than aerial cars, with a maximum of $7 \mathrm{~m} / \mathrm{s}$ for bi-cable gondolas and a maximum of $6 \mathrm{~m} / \mathrm{s}$ for monocable gondolas (CEN 2004). Dwell times are shorter than aerial cars, as the cabins are smaller. Passengers do not need to wait for the vehicles at the station, as the vehicles constantly come and go. The spans between the pylons are smaller than aerial tramways because there is more than one vehicle on the rope at a time, and the lengths of gaps and precipices over which cabins can travel are smaller than for the aerial tramways. When at a station, cabins do not stand still but move slowly through the station, which can make it difficult for persons with disabilities and older adults to enter. Time of entry into the cabin is limited depending on the speed and length of the platform.

Gondolas are the more suitable for public passenger transport, which requires maximum capacity. Aerial tramways are faster; the speed of a gondola-21-25 km/h-is less than the average speeds of buses in urban centers. Tirachini (2013) measured the average speed of city buses, at $38.9 \mathrm{~km} / \mathrm{h}$, which during peak hours reduces to 34.4 $\mathrm{km} / \mathrm{h}$. The speeds of cable cars are low but, in the case of gondolas, the vehicles come constantly into stations and passengers do not need to wait for them. Aerial cable 
car lines can travel outside over streets and buildings, and the distance between the stations can be shorter.

It is clear that the capacities of aerial cars are not competitive with the existing, moreused modes of passenger transport in urban centers. According to the Transport Research Board (2003) and Clement-Werny et al. (2011), types of transport in urban centers have the following capacities:

- Single traffic lane for passenger cars - up to 9,000 persons/h (2,250 passenger cars/h, 4 persons per vehicle)

- Metro - up to 36,000 persons/h

- Buses within mixed traffic - up to 1,250 persons/h

- Light rail on streets - to 11,800 persons/h (tram)

- Bus lanes - up to10,000 persons/h

- Bus rapid transit - 9,000-35,000 persons/h (Transmilenio Bogotá)

- Light rail - up to 19,000 persons/h (exclusive row)

- Heavy rail - up to 49,000 persons/h

These capacities may vary under different conditions of use, but they are much greater compared to the capacities of aerial cable cars, which have maximum capacities of up to 2,000 persons/ $h$ for an aerial tramway and up to 4,000 persons/ $h$ for gondolas.

Dwell times are short for gondolas, as the cabins are small (usually 6-8 persons, maximum 30). Average dwell time for a bus of 10 people is around 22 seconds and for 30 people around 43 seconds, as noted Rexfelt et al. (2014). A problem for buses can be the times necessary for payment and validation of tickets; for cable cars, this can be done outside the vehicle before entering the platform.

\section{Methodology}

Based on existing operating modes of cable cars, a geometrical model of a station was developed that included all the essential elements that affect passenger entry and exit. A CAD program was used for implementing this geometric model, with the possibility of 3D modeling. Based on the geometric model, a model was established for calculating the capacities and other properties of cable cars. The same methodology was used for new proposals of cable cars with improved characteristics. First, a geometric design that included new ideas presented in this paper (see Figures 2, 3, and 6) was implemented within the model and then was based on the establishment of a calculation model. Based on the results, the new model of cable car was compared with existing systems of passenger transport in urban environments.

\section{Existing Procedures and New Models of Passenger Entry and Exit}

Depending on the identified limitations of cable car transport, primarily small capacity, it should be possible to increase the capacities of gondolas by using two platforms for entry and exit at stations. 


\section{Existing System of Entry and Exit for Gondolas}

The existing system for gondolas is to use only one platform for boarding (Figure 1). The vehicle has a maximum speed of $0.5 \mathrm{~m} / \mathrm{s}$, and the minimum distance between vehicles in a station is $0.5 \mathrm{~m}$ (CEN 2004).

FIGURE 1.

Existing system of gondolas - passenger entry and exit in station

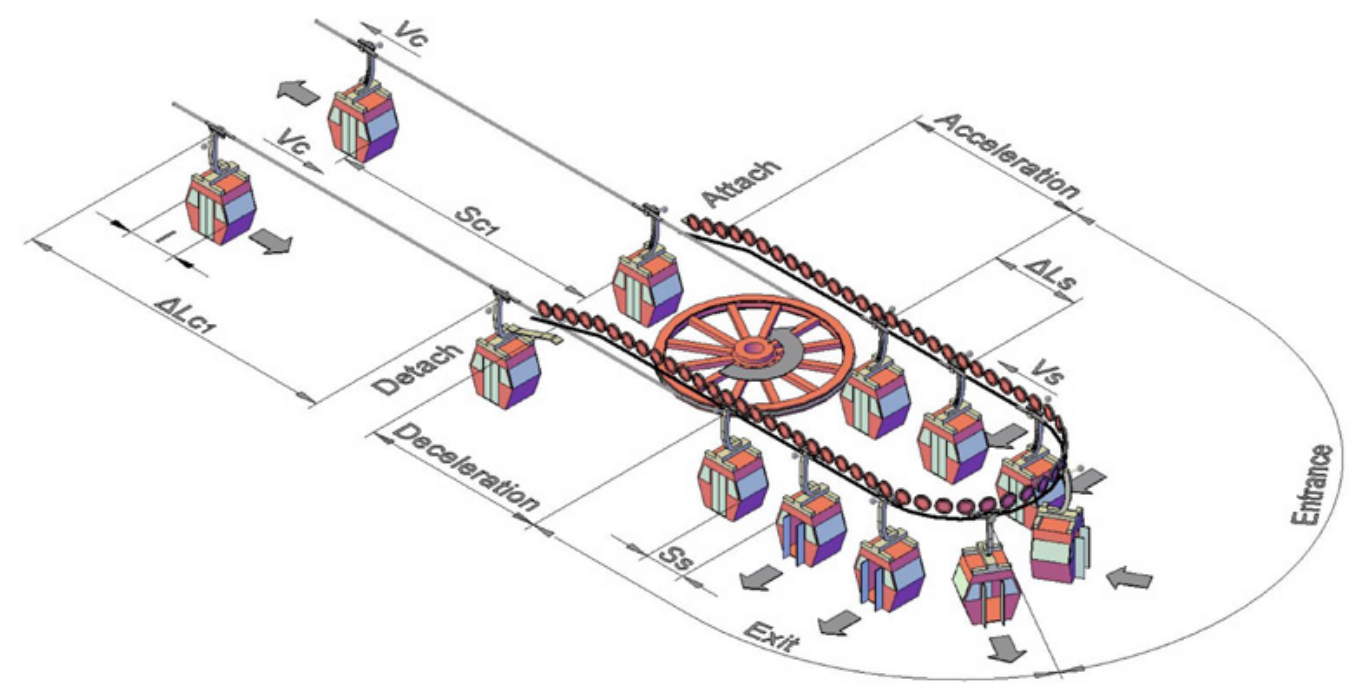

Operating gondolas with detachable grips within a station is as follows. When the vehicle is connected to the rope and located on the line, it moves with the speed of a cable car on the line $\left(V_{c}\right)$. When it comes into the station, the grip detaches from the rope, and the cabin starts to brake by using friction discs with rubber rings that touch the top of the grip. When the cabin reaches a low speed within the station $\left(V_{S}\right)$, it moves by friction conveyor through the station. The doors open and the exit starts, and then passengers enter the cabins. After the turn, when the cabin reaches the end of the platform, the doors close and acceleration begins. The grip attaches to the rope, and the cabin leaves the station at the speed of a cable car on the line $\left(V_{C}\right)$.

Calculations were made based on Težak (2012): spacing or pitch (CEN 2005) on unidirectional installations is the distance between two successive carriers, group of carriers, or tow hangers. If the length of the vehicle is $3 \mathrm{~m}$ and the minimum distance between vehicles in the station is $0.5 \mathrm{~m}$, the minimum spacing between vehicles in the station is:

$$
\Delta 1_{\mathrm{s}}=3+s_{S}=3+0,5=3.5 m
$$

where,

$$
\begin{aligned}
& \Delta 1_{\mathrm{S}}=\text { spacing between vehicles while in the station (m) } \\
& s_{S}=\text { distances between vehicles (cabins) in the station (m) }
\end{aligned}
$$

On the basis of the maximum speed of vehicles in the station and the minimum spacing between vehicles in the station, the minimum interval between vehicles can be calculated: 


$$
\Delta \mathrm{t}_{\mathrm{S}}=\frac{\Delta \mathrm{l}_{\mathrm{S}}}{\mathrm{V}_{\mathrm{S}}}=\frac{3.5}{0.5}=7 \mathrm{~s}
$$

where,

$$
\begin{aligned}
& \Delta \mathrm{t}_{s}=\text { intervals between vehicles in the station (s) } \\
& V_{\mathrm{s}}=\text { speeds of vehicles in the station }(\mathrm{m} / \mathrm{s})
\end{aligned}
$$

As only one platform is used, the minimum intervals between vehicles in the station and on the line are the same:

$$
\Delta \mathrm{t}_{s}=\Delta \mathrm{t}_{c}
$$

where,

$$
\Delta \mathrm{t}_{c}=\text { interval between vehicles on the line (s) }
$$

The maximum capacity of the gondola depends on the minimum interval between vehicles and the number of persons in the vehicle. If the number of persons in the vehicle is 8 , the theoretical capacity of the gondola is:

$$
\mathrm{Q}_{C}=\frac{3600}{\Delta \mathrm{t}_{C}} \cdot \mathrm{n}=\frac{3600}{7} \cdot 8=4114 \text { persons } / \mathrm{h}
$$

where,

$$
\left.\mathrm{Q}_{c}=\text { capacity of the gondola (persons } / \mathrm{h}\right)
$$

However, in practice, the minimum interval of $7 \mathrm{~s}$ by the gondolas is not applied. Only for chair lifts and surface lifts are such small intervals used (CEN 2004). For gondolas with the highest capacities, the interval between vehicles is somewhere around $12 \mathrm{~s}$. For example, a gondola in Medellin has a capacity of 3,000 persons/h, 10 persons in one vehicle, and intervals between vehicles of $12 \mathrm{~s}$ (Brand 2011). Gondolas with the highest capacities have cabins with several passengers and achieve maximum capacities of somewhere around 4,000 persons/h.

The described example shows that more vehicles could not be accommodated within stations, as the calculation is made based on the minimum required spacing between vehicles in the station. The spacing between the vehicles on the line depends on the relationship between the speed of the vehicles in the station and the speed on the line:

$$
\Delta \mathrm{l}_{\mathrm{C}}=\frac{\Delta \mathrm{l}_{\mathrm{S}}}{V_{S}} \cdot V_{C}=\frac{3.5}{0.5} \cdot 6=42 \mathrm{~m}
$$

where,

$V_{c}=$ speeds of the cable cars - speeds of vehicles on the line $(\mathrm{m} / \mathrm{s})$

$\Delta 1_{\mathrm{c}}=$ space between vehicles on the line $(\mathrm{m})$ 
The maximum speed for a cable car with a closed carrier (gondola) with one carryinghauling rope is $6 \mathrm{~m} / \mathrm{s}$, which has $12 \mathrm{~s}$ of interval between vehicles and a space between vehicles of $72 \mathrm{~m}$. If the calculated space between vehicles is lower than $42 \mathrm{~m}$, then there would be insufficient space in the station between vehicles. When comparing the distances between cable cars and distances between vehicles in road transport, it can be see that the distance of $42 \mathrm{~m}$ or $72 \mathrm{~m}$ is quite high (in cases in which vehicle speeds are low), and there are possibilities for reducing this space. Also, the interval between vehicles on the cable car line, which in this case is $7 \mathrm{~s}$, is fairly high and is much greater than for transport by road.

\section{System with Two Platforms for Entry and Exit of Gondolas}

A system with two station platforms for gondolas is shown in Figure 2. Two platformsone internal and one external-are placed at the same level. Each platform has a separate line for vehicle braking, transporting, and accelerating, and both platforms use the same zone for detaching and attaching grips on the rope. Cabin entry into the station for both platforms is at the same place, and when it detaches from the rope, it starts braking for the internal or external platform. Cabins alternate between the internal and external platforms.

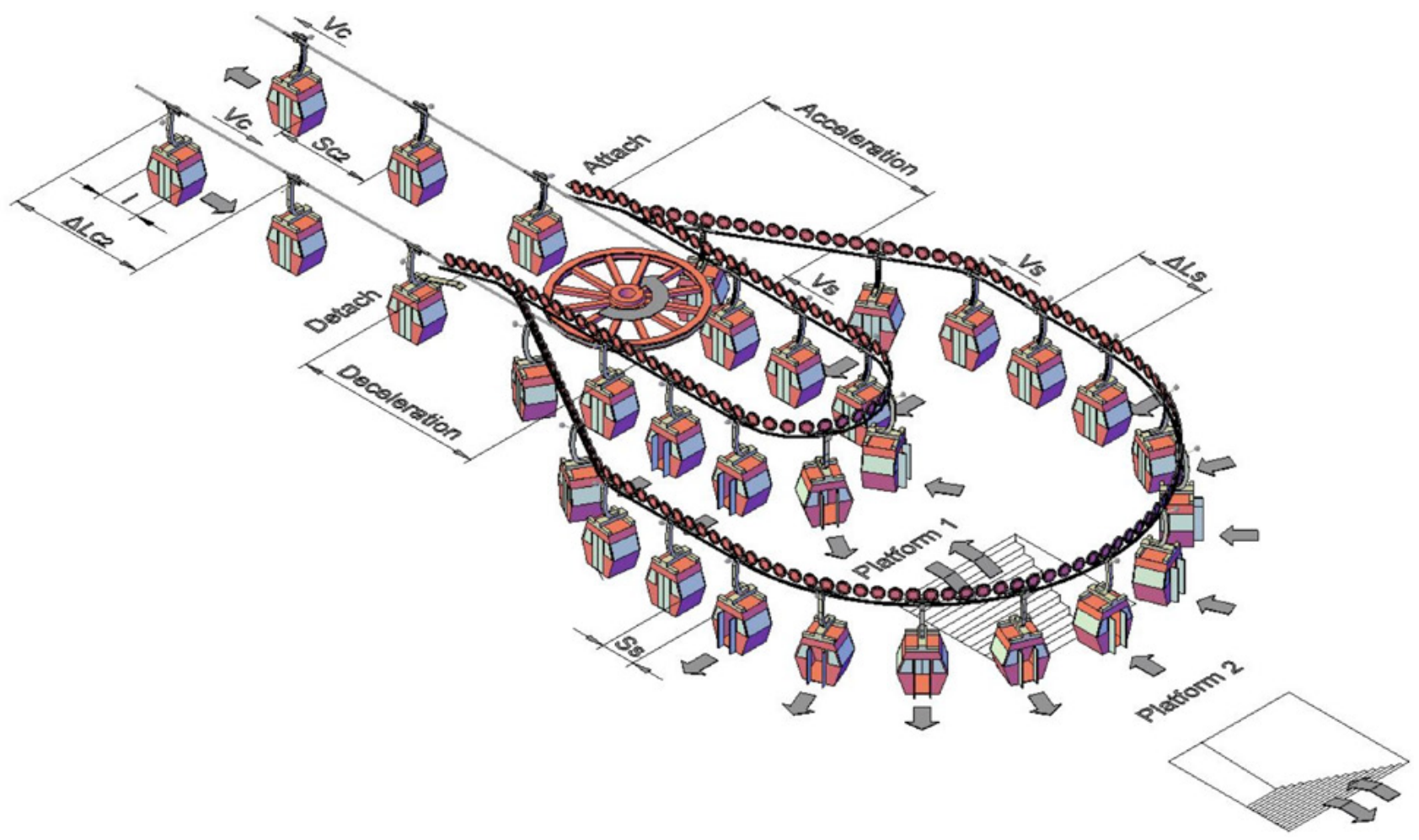

FIGURE 2. System of two gondola platforms on same level - passenger entry and exit 
The procedure of entry and exit from slowly-moving cabins takes place separately at the internal and external platforms, where acceleration of the cabins is separate. Only before the zone of attaching the grips onto the rope, where the cabin has the same speed as the rope $\left(V_{c}\right)$, do the internal and external lines merge. All cabins leave the station at the same place. Passenger access to the internal platform runs through the underpass under the external platform.

This system could solve the problem of distances between vehicles that are too great on the line of the cable cars.

In this case, vehicle speeds $(0.5 \mathrm{~m} / \mathrm{s})$ and minimum distances between vehicles in the station $(0.5 \mathrm{~m})$ are the same as in Figure 1 for the existing system of gondolas with one platform. It is also the same minimum time interval for vehicles in the station (7 s).

However, with the use of two platforms in the station, the minimum interval between vehicles on the line is reduced by twofold and at $3.5 \mathrm{~s}$ would already be close to the time intervals of passenger cars in road transport, which is around $2 \mathrm{~s}$.

$$
\Delta \mathrm{t}_{C 2}=\frac{\Delta \mathrm{lt}_{\mathrm{s}}}{2}=\frac{7}{2}=3.5 \mathrm{~s}
$$

where,

$$
\Delta \mathrm{t}_{c_{2}}=\text { interval between vehicles on the line for gondolas with two platforms (s) }
$$

It also would reduce the spaces between the vehicles on the line twofold:

$$
\Delta 1_{\mathrm{c} 2}=\Delta \mathrm{t}_{c 2} \cdot V_{c}=3.5 \cdot 6=21 \mathrm{~m}
$$

where,

$\Delta 1_{c 2}=$ spacing between vehicles on line for gondolas with two platforms (m)

The capacities of gondolas with two platforms in the station would be increased twofold and in this case would be:

$$
\mathrm{Q}_{C 2}=\frac{3600}{\Delta \mathrm{t}_{C 2}} \cdot \mathrm{n}=\frac{3600}{3,5} \cdot 8=8228 \text { persons } / \mathrm{h}
$$

where,

$\mathrm{Q}_{c 2}=$ capacities of the gondolas with two platforms (persons $/ \mathrm{h}$ )

The disadvantage of this system is that due to the larger radius of the line on the external platform, there would be a greater number of cabins, as in the internal platform, which would increase the costs of the device. Cabins would not leave the station in the same order as they entered the station. As there would be two platforms, the surface of the floor in the station would have to be much greater. This weakness could be removed by using two platforms on two different floors, as shown in Figure 3 . Each floor would have separate lines for the braking, transporting, and acceleration of 
cabins. In this case, the surface of the ground plan in the station would be smaller and the number of vehicles in the station less than if both platforms were on the same level (Figure 2).

FIGURE 3.

System of two platforms for gondola on two different floors - passenger entry and exit

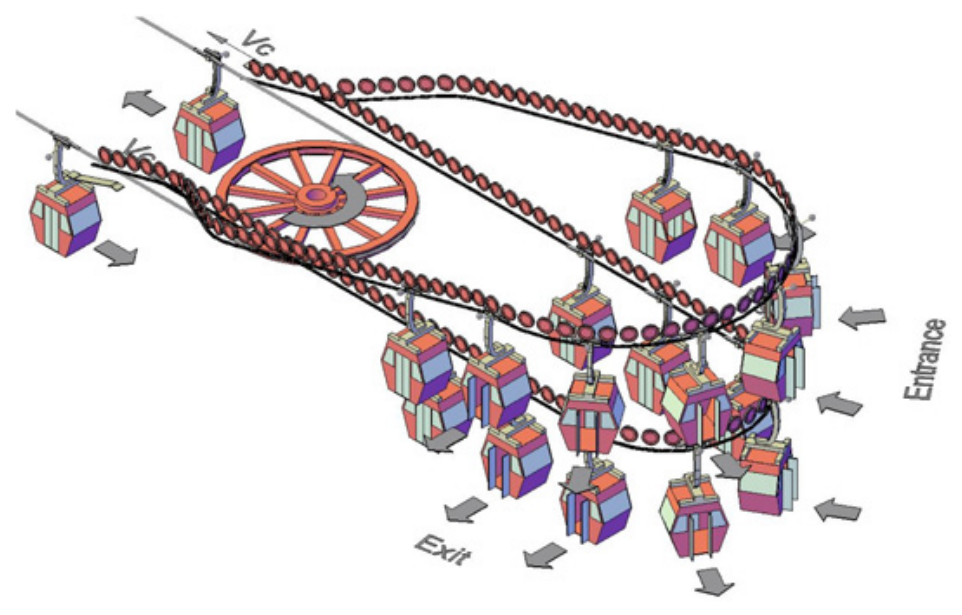

\section{Transportation Characteristics of Gondolas with Two Platforms}

The described system of gondolas with two platforms, which would reduce the distances between vehicles on the line, could increase the capacity of cable cars twofold and, therefore, the cable cars could reach capacities of up to 8,000 persons/h. Such capacity would be comparable to the capacities of other high-performance systems designed to carry persons in public passenger transport. The top speed of such devices in relation to regulations would remain $6 \mathrm{~m} / \mathrm{s}(21.6 \mathrm{~km} / \mathrm{h})$ for mono-cable systems and 7 $\mathrm{m} / \mathrm{s}(25.2 \mathrm{~km} / \mathrm{h})$ for bi-cable systems.

Figure 4 shows the transportation characteristics of certain types of cable cars. The maximum speeds and capacities are achieved by funiculars, but they are not aerial cable cars and do not have the advantages of transport in the air in urban centers, where there are crowded streets. The fastest aerial cable cars are aerial tramways, but they have small capacities. Gondolas with two platforms would have double the capacity of normal existing gondolas.

FIGURE 4.

Comparison between gondolas with two platforms and other types of cable cars
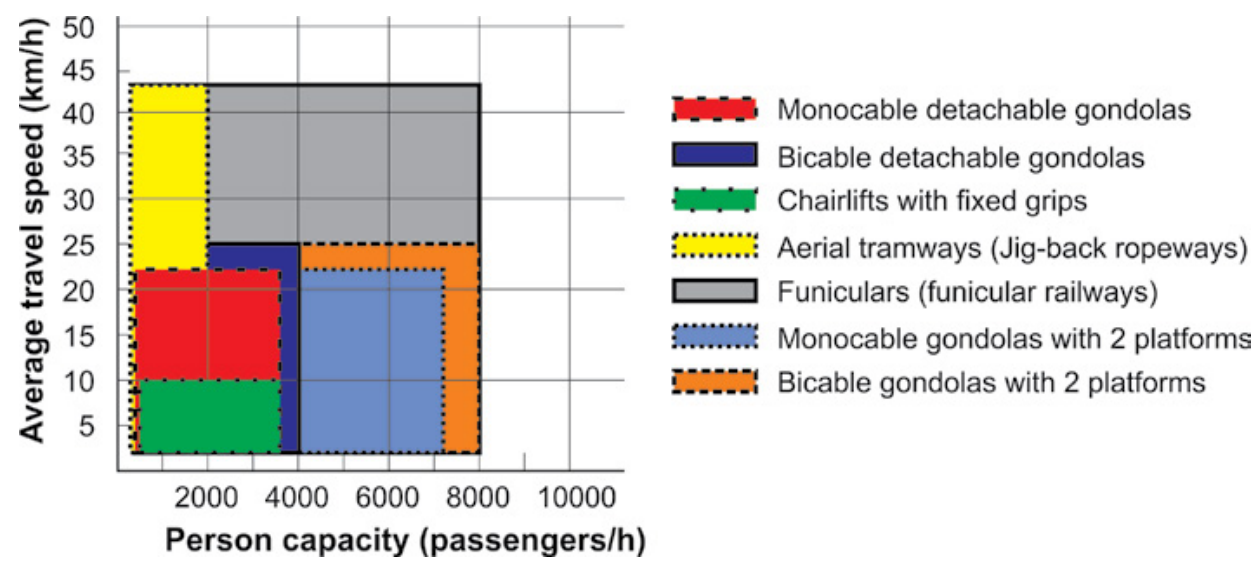
A disadvantage of gondolas is also the difficulty of access for persons with disabilities and older adults because the vehicles in the station do not stop completely (as with aerial tramways or funiculars). To facilitate the entry of these passengers, it should be necessary to stop the gondola. If the gondola stops every 15 minutes, entry of persons with disabilities and older adults takes 30 seconds, and exit takes 30 seconds, the gondola stops 8 times per hour. This is 4 minutes of inactivity, which represents a $6.66 \%$ reduction in passenger capacity for gondolas.

A gondola has, by its implementation, a distinct safety advantage over a road vehicle. A sudden stop of the carrying-hauling rope will cause swaying of all cabins and the cabins will start rotating. The deceleration force would not eject passengers from the cabin (as in a car), but would work on the force of the passengers in a direction perpendicular to the ground of the rotating cabin. Therefore, there would be no collision between cabins after the sudden braking or stopping of the gondola (Figure 5).

FIGURE 5.

Unique swaying of vehicles in event of sudden stop of gondola

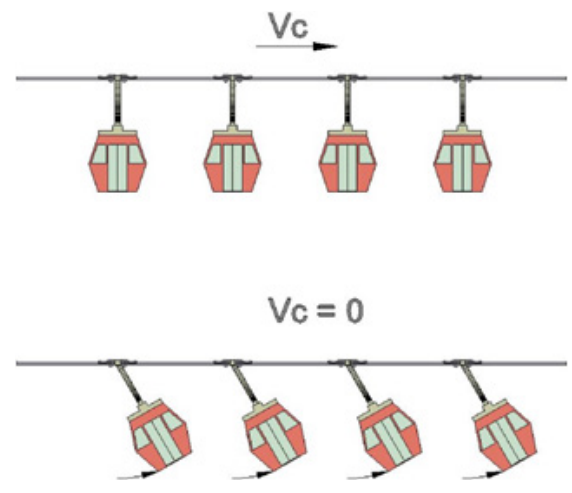

In theory, in stations, different numbers of platforms could be added, which could be placed on different floors. However, if there are too many vehicles on the line, insufficient safety distances could occur, so, in accordance with regulations (CEN 2004), longitudinal swaying of vehicles must be possible due to different effects such as impacts of wind, dynamic forces, etc.

Another advantage of gondolas is that they use small vehicles. This means that in the intermediate stations on the line, it is not necessary to stop all cabins, only those from which passengers exit. Special construction of intermediate stations, as shown in Figure 6 , could allow this. Using this measure, passengers in other cabins could smoothly travel to other or final stations. Figure 6 shows that every fourth cabin detached from the rope and wheel conveyor leads it to a lower level with the speed of the rope $\left(V_{c}\right)$. Then, the grip detaches from the rope and the cabin starts braking by using friction discs with rubber rings, which touch the top of the grip. When the cabin reaches a low speed in the station $\left(V_{s}\right.$, which is less than $\left.0.5 \mathrm{~m} / \mathrm{s}\right)$, it moves by a friction conveyor through the station. The door opens, and passenger exit and entry from/into the cabins begins. After that, when the cabin reaches the end of the platform, the door closes and then starts accelerating to the speed of the rope. The wheel conveyor leads the cabin to the higher level, where the grip attaches to the rope, and the cabin leaves the station with the speed of the rope on the line $\left(V_{C}\right)$. 


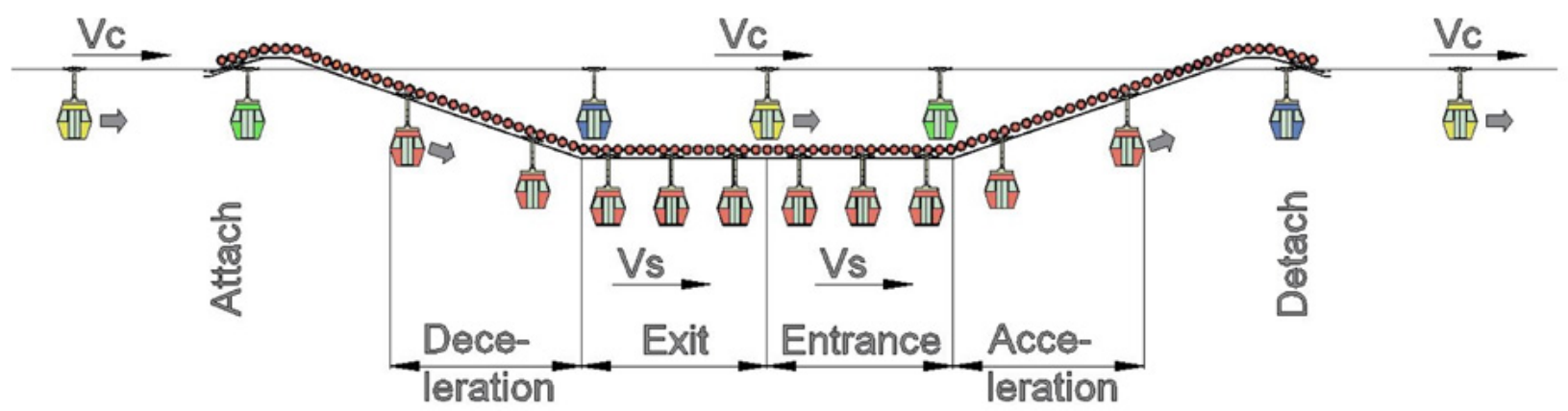

FIGURE 6. Intermediate station that stops every fourth cabin

The advantage of such a station is that the cabin comes down to the level of the ground, which could be a street surface. The disadvantage is that more cabins in the station are necessary because they are slower-moving than other cabins on the rope. A cabin leaving the station must be attached at the same place on the rope as a cabin entering the station.

For passengers to know which cabin will be stopping at one of the intermediate stations, the cabins could be differently marked with the inscription of the intermediate station or have different colors-for example, a yellow cabin stops at the first intermediate station, green at the second, red at the third, and blue at the fourth. At the end, cabins come into the final station.

\section{Price Comparisons with Cable Car Systems}

As stated by Clement-Werny at al. (2011), investment costs of existing mono-cable gondolas in mountain areas are as follows:

- Drive station $-3,000,000 €$

- Intermediate station $-1,500,000 €$

- Return station $-1,000,000 €$

- Cabin (8-10 person) $-30,000 €$

- Pylon - 100,000€

- Carrying-hauling rope $-100,000 €$

The cost of a mono-cable gondola with a capacity of 3,000 persons/h with 100 cabins and 20 pylons without intermediate stations would be about $\$ 11$ million US. However, this does not include the price of the land and the preparation for construction, which in urban environments can be very expensive. For example, the cost of a gondola in Maribor, which is not in an urban area, is $\$ 13.9$ million US (12.2 million $€$ ), which includes 82 cabins, 19 pillars, a drive station, a return station, and one intermediate station. The cost for gondola LINE L in Medellin (93 cabins, 20 pylons, 2 intermediate stations) is $\$ 24$ million US (Brand and Davila 2011). In Maribor, the new cable car was set up on the old site, which meant that the land was already purchased. In Medellin, a new cable car was set up at a new location in the city, which is a more expensive investment. 
Thus, the average price for mono-cable gondolas per km length in Medellin for the line $\mathrm{L}$ was $\$ 11.6$ million US/km, and in Maribor it was $\$ 5.5$ million US $/ \mathrm{km}$.

Is a gondola with two platforms in the stations less expensive than the two parallel gondolas with the existing configuration in the stations? The construction characteristics of cable cars are calculated according to the maximum force on the rope, which depends of the altitude, force of friction, weight of cargo, weights of rope and empty vehicles, and tension and dynamic forces at the drive device (Nejez 2006). A disadvantage of mono-cable gondolas is that the weight of the carrying-hauling rope is quite high. The weight ratio of cargo, empty cabins, and carrying-hauling rope is somewhere around 30:30:40. So if the increase in capacity is twofold, then the increased weight of cargo, the number of cabins, and the weight of carrying-hauling rope also are twofold.

At twice the maximum tension force on the rope, the diameter of the rope has to increase by $41 \%$, so the weight of the rope per meter doubles. The pylons need to be stronger, roller batteries would have to have sheaves with larger diameters, and the number of sheaves in the roller battery would have to be greater. The drive system of a cable car with a twofold greater capacity also would have to have double power of the electric motor. The costs for intermediate stations would be similar to existing conventional gondolas and gondolas with two platforms at the ending stations. Similarly, the cost of a drive station and a return station would not be twice as expensive.

In the end, it can be concluded that the price of gondolas with two platforms in stations would be slightly lower than for two parallel conventional gondolas. However, the gondola would have a greater impact on visual appearance in urban environments and would be better if using only one line instead of two. It is estimated that the cost for a gondola with two platforms at the ending stations, which would achieve a capacity of $6,000-8,000$ persons/h, would be $\$ 11-20$ million US per $\mathrm{km}$ of line. Depending on the observed values of the investment costs in the public transport system, as delivered by Gardner (1996), this would be higher than the price of investment in a tramway transport system ( $\$ 5-15$ million US per $\mathrm{km}$ ), which has a similar capacity.

\section{Conclusion}

Cable car transport has many advantages compared with other modes of passenger transport, such as clean electricity drive, high levels of safety for passengers, and quiet operation. The most important characteristic is that cable car transport can be installed in the air over streets in urban areas, independent of congestion. However, cable cars, in spite of the advantages, still cannot achieve certain characteristics of other modes of transport, such as capacity or number of passengers per hour.

This paper has demonstrated that cable car transport can become competitive with other types of passenger transport in urban areas. With additional platforms in gondola stations, it is possible to achieve reduced distance (intervals and spacing) between vehicles on the line and increase capacity. In this way, the necessary surfaces for passenger entry and exit in the cabins increases, which is necessary for passenger 
transport with large capacities. More important, any given solution would have to take into account the existing technologies related to gondolas, such as detachable grips, acceleration and braking of cabins, and use of existing wheel conveyors that are moving vehicles through the station. The difference would be that there would be two separate platforms in the stations with systems for the braking, moving, and accelerating of cabins. Even while on the line, the same technology would be used, except the vehicles on the line would be better sorted, which would increase the efficiencies of the cable cars.

Gondolas also have advantages because of smaller vehicles. This means that at intermediate stations on a line, it would not be necessary to stop all cabins, but only those in which passengers would like to exit; other vehicles could freely travel to the other stations. Gondolas with two platforms in a station with twofold greater capacity would be more expensive but not twice as expensive as existing conventional gondolas with one platform. The price for a mono-cable gondola with two platforms in a station would be $\$ 11-20$ million US per $\mathrm{km}$.

\section{References}

Abcde-institute.org. 2015. "Urban Ropeways. The Optimal System." http://www.abcdeinstitute.org/urban_ropeways_the_optimal_system.html, accessed June 5, 2015.

Bocareo, J. P., J. P. Portilla, J. M. Velásquez, M. N. Cruz, A. Peńa, and D. R. Oviedo, D.R. 2014. "An Innovative Transit System and Its Impact on Low Income Users: The Case of the Metrocable in Medellin." Journal of Transport Geography, 39: 49-61.

Brand, P., and J. D. Davila. 2011. "Aerial Cable-Car Systems for Public Transport in Low-Income Urban Areas: Lessons from Medellin, Colombia." $3^{\text {rd }}$ World Planning Schools Congress, Perth (WA), 4-8 July 2011, http://r4d.dfid.gov.uk/PDF/Outputs/ ESRC_DFID/60726_Brand_aerial.pdf, accessed June 18,2015.

Brida, J. G., M. Deidda, and M. Pulina. 2014. "Tourism and Transport System in Mountain Environments: Analysis of the Economic Efficiency of Cableway in South Tyrol." Journal of Transport Geography, 36: 1-11.

CEN (European Comitee for Standardization). 2004. "EN-12929-1. Safety Requirements for Cableways Installation Designed to Carry Persons - General Requirements Part 1: Requirements for All Installations." CEN/TC 242, Brussels.

CEN (European Comitee for Standardization). 2005. “EN-1907, Safety Requirements for Cableways Installation Designed to Carry Persons - Terminology." CEN/TC 242, Brussels.

Clement-Werny, C., D. Dubois, A. L. Ruyet, M. Potier, S. Rousic, and Y. Schneider. 2011. "Aerial Ropeways as Urban Transport Systems." Certu-STRTMG-CETE, http:// www.strmtg.developpement-durable.gouv.fr/IMG/pdf/cableways_MEDDLT_ december2011.pdf, accessed June 5, 2015. 
Dávila, J. 2013. "Urban Mobility and Poverty: Lessons from Medellín and Soacha, Colombia." London, DPU, UCL and Universidad Nacional de Colombia, http:// www.bartlett.ucl.ac.uk/dpu/metrocables/book/english, accessed June 24, 2015.

Doppelmayr, A. 1997. Denkastosse zur Funktionseerfülung von Einseilumlaufbhnen, Projektirung und Konstruktion im Sicherheitsregelkreissystem, basoerend auf der Aanalyse von Vorfällen. ISBN 3-9500815-0-X, Wolfurt, Austria.

Gardner, G. 1996. "Decision Making and Infrastructure Projects.” VII Conference on Urban Transport and Integrated Development, New Delhi, February 1996, http://www.transport-links.org/transport_links/filearea/documentstore/249_ PA3143_1996\%5B1\%5D.pdf, accessed June 18, 2015.

Günthner, W.A. 1999. Seilbahntechnik. Technische Universität München, München.

Heinrichs, D., and J. S. Bernet. 2014. "Public Transport and Accessibility in Informal Settlements: Aerial Cable Cars in Medellín, Colombia." Transportation Research Procedia 4: 55-67.

ISR - Internationale seilbahn-rundschau. (2015). "Größtes urbanes Sailbahnnetz komplett," $1-18$.

Nejez, J. 2006. Vorlesung aus Seilbahnbau. Technische Universität Graz, Graz

Nikšić, M., and S. Gašparović. 2010. "Geographic and Traffic Aspects of Possibilities for Implementing Ropeway Systems in Passenger Transport." Promet Traffic \& Transportation, 22 (5): 389-398.

Oplatka, G. 2008. "Seilbahnen - sicheres Verkehrsmittel in den Bergen - Wohin die technischen Trends gehen In." NZZ Online, http://www.nzz.ch/lebensart/automobil/die-vielen-gesichter-der-seilbahn-1.832644, accessed June 5, 2015.

Rexfelt, O., T. Schelenz, M. Karlsson, and A. Suescun. 2014. "Evaulating the Effect of Bus Design on Passenger Flow: Is Agent-Based Simulation a Feasible Approach?" Transportation Research Part C: Emerging Technologies, 36: 1-11.

Sever, D. 2002. "Some New Methods to Assure Harmonisation of Sustainable Development of Mountain Resorts Ropeway." Promet 14 (5): 213-220.

Težak, S. 2012. "Modern Cableways - The Base of Mountain Sports Tourism, Strategies for Tourism Industry - Micro and Macro Perspectives." Dr. Murat Kasimoglu (ed.), DOI 10.5772/38541, http://www.intechopen.com/books/strategies-for-tourismindustry-micro-and-macro-perspectives/modern-cableways-the-base-of-mountainsports-tourism, accessed June 6, 2015.

Tirachini, A. 2013. "Estimation of Travel Time and Benefits of Upgrading the Fare Payment Technology in Urban Bus Service." Transportation Research Part C: Emerging Technologies, 30: 239-256.

Transportation Research Board. 2003. Transit Capacity and Quality of Service Manual, 2nd Edition, http://www.trb.org/Main/Blurbs/Transit_Capacity_and_Quality_of_ Service_Manual_2nd_153590.aspx, accessed June 8, 2015. 
Wu, H., X. W. Wu, H. Q. Huang, and H. J. Wang. 2013. "The Role and Development Prospects in the Ropeway in Urban Transport System, Resources and Sustainable Development."PTS 1-4, Book Series: Advanced Materials Research, 734-737: 16411644.

\section{About the Authors}

SERGEJ TeŽAK (sergej.tezak@um.si) is an Assistant Professor at the University of Maribor, Faculty of Civil Engineering, Transportation Engineering and Architecture, Department of Transportation Engineering, where he studies and teaches about quality management in public transport, cableway transport, and geometric modeling.

Drago SeVer (drago.sever@um.si) is an Associate Professor of traffic technique and transportation technology and Chair of the Transportation Technology and Organisation, Faculty of Civil Engineering, Transportation Engineering and Architecture, University of Maribor. His areas of interest include transportation technology, public transport, and cableway transport.

MARJAN LeP (marjan.lep@um.si) is an Assistant Professor of traffic planning and modeling and transport informatics and head of the Department of Transportation Engineering, Faculty of Civil Engineering, Transportation Engineering and Architecture, University of Maribor. 